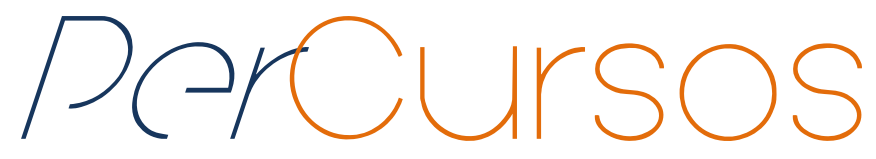

\title{
Informação, ética e tecnologia. Uma entrevista com o Professor Enrique Muriel-Torrado
}

O Professor Enrique Muriel-Torrado possui graduação em Biblioteconomía y Documentación pela Universidade de Extremadura, Licenciatura em Documentación pela Universidade de Extremadura, Mestrado em Información Científica - Universidad de Granada, Mestrado em Documentación Digital - Universitat Pompeu Fabra, Doutorado em Documentación - Universidad de Granada e Pós Doutorado na UFSC. Tem experiência na área de Vigilância Tecnológica, com ênfase em Ciência da Informação, atuando principalmente nos seguintes temas: Copyleft, Creative Commons, Copyright, direitos autorais, e competência informacional. Atualmente pesquisa sobre serviços e ferramentas tecnológicas em unidades da informação. É Professor da Universidade Federal de Santa Catarina - UFSC e está vinculado ao grupo de pesquisa Inteligência, Tecnologia e Informação - Research Groupl - ITI-RG.

Entrevista concedida em: 30/09/2016

\section{Entrevistadores}

Daniella Camara Pizarro

Doutoranda em Ciências da Informação na Univ. Federal de Santa Catarina - UFSC. Professora da Univ. do Estado de Santa Catarina - UDESC Brasil daniellapizarro@hotmail.com

\section{Divino Ignácio Ribeiro Júnior}

Doutor em Engenharia e Gestão do Conhecimento pela Univ. Federal de Santa Catarina - UFSC. Professor da Univ. do Estado de

Santa Catarina - UDESC Brasil divinoirj@gmail.com

\section{José Eduardo Santarem Segundo Doutor em Ciência da Informação pela Univ. Estadual Paulista Júlio de Mesquita Filho-UNESP- Marília/SP. Professor da Univ. de São Paulo - USP Brasil santarem@usp.br}

\section{Para citar esta entrevista:}

MURIEL-TORRADO, Enrique. Informação, ética e tecnologia. Uma entrevista com o Professor Enrique Muriel-Torrado. [Entrevista concedida em 30 de setembro de 2016]. Revista PerCursos. Florianópolis, v. 17, n.34, p. 134 - 140, maio/ago. 2016. Entrevistadores: Daniella Camara Pizarro, Divino Ignácio Ribeiro Júnior e José Eduardo Santarem Segundo.

DOI: $10.5965 / 1984724617342016134$

רttp://dx.doi.org/10.5965/1984724617342016134 
PerCursos: Atualmente, as tecnologias influenciam substancialmente na forma de acesso e apropriação da informação por parte dos indivíduos. No caso da mídia tradicional, observamos fontes de informação, como a Internet, Televisão e Rádio, as quais, muitas vezes, têm efeito contrário: ao invés de informar, elas "desinformam". O que é necessário para se faça uma boa escolha das fontes de informação?

Enrique Muriel-Torrado: Se falarmos de informação científica, existem muitas instituições e profissionais encarregados de pesquisar, gerenciar, compartilhar e publicar este tipo de informação para a área que precisarmos. No âmbito da ciência, a informação passa pelo filtro da comunicação científica, que ajuda a identificar informações erradas, com metodologias incorretas ou incompletas, entre outros, mediante a revisão por pares quando submetemos um artigo a uma revista.

No caso da informação jornalística ou geral, muda um pouco. A influência das grandes mídias na população é maior, e geralmente atrás das grandes companhias existem fortes interesses econômicos privados. Manuel Castells em "O Poder da Comunicação" trata alguns dos problemas da mídia e o poder que exerce sobre a população. Com a internet, mudou a comunicação unidirecional dos jornais ou os noticiários da TV para uma comunicação em que o usuário também participa e interatua com a informação, no que agora se denomina segunda tela.

Por um lado, é uma boa notícia, por outro, sem a formação mínima necessária, as informações acessadas não serão de muita utilidade se a população não tem as competências para diferenciar entre informações objetivas e subjetivas.

Não devemos olvidar que atrás das fontes de informação, científicas ou periodistas, estão os humanos. Não podemos exigir que os cientistas ou jornalistas sejam 100\% éticos se a sociedade não é, porque como acontece com os políticos, eles sãos simplesmente um reflexo da sociedade; se a sociedade é corruta, também veremos corrupção nas informações ou nas fontes em que se encontram.

Neste sentido, ter uma boa competência informacional é fundamental para reduzir, na medida do possível, a chance de sermos manipulados ou enganados. 
PerCursos: Ao pensar mais especificamente na Internet e na sua amplitude e abrangência, ficamos sujeitos a algum tipo de censura, ocultação ou manipulação de informação quando obtemos resultados de uma determinada busca?

Enrique Muriel-Torrado: O buscador quase onipresente nas buscas dos usuários no mundo inteiro, Google, oferece resultados conforme os nossos interesses, ou melhor, segundo os interesses que a corporação estadunidense considera que são os interesses dos seus usuários, porque eles fazem um perfil muito completo de cada um de nós. Há uns anos, quando o buscador operava na China, fiz um pequeno teste procurando "Praça Tiannamen" no Google Imagens dos EUA, Espanha, França, Itália e China (e ampliei um tempo depois em: Las principales formas de censura en internet [http://enriquemuriel.prof.ufsc.br/las-principales-formas-de-censura-en-internet-

actualizado/]). Os resultados dos quatro primeiros países eram parecidos: a icônica imagem de um homem de calças pretas e camisa branca, com uma maleta e uma sacola nas mãos parado frente a um fila de tanques de guerra. A imagem é um ícone mundial da resistência contra o poder. Quando se procurou o mesmo termo na versão chinesa do buscador, apenas apareciam imagens da praça na atualidade, sem aparecer nenhuma imagem relacionada com a forte repressão acontecida nesse lugar. Os resultados estavam "filtrados"

Hoje, o Google não opera mais na China, mas sua forma de atuar continua sendo a mesma. Por exemplo, Google Maps muda as fronteiras dependendo de onde o acessemos (2, http://www.popsci.com/does-google-create-worlds-borders ). Já existem algumas vozes que consideram que deveria existir um motor de busca público que garanta que os resultados apresentados não apresentam manipulação, ocultação e nenhum tipo de censura. Poderíamos ampliar este raciocínio para a criação de um organismo público internacional para a preservação dos conteúdos na web.

Seja como for, o papel do profissional da informação e da competência informacional deve ser protagonista para orientar os usuários nestas e em outras questões. 
PerCursos: Com relação às mídias sociais, como Facebook e Youtube, por exemplo, quais os principais problemas observados na questão referente ao compartilhamento de materiais e aos direitos autorais?

Enrique Muriel-Torrado: O principal problema que existe com os direitos autorais é que as pessoas não conhecem nem, geralmente, tem interesse em conhecê-los. Uma pergunta clássica quando pesquisamos em algum trabalho sobre o assunto é: "O que precisamos fazer para obter os direitos de autor sobre uma obra que criamos?". Poucas pessoas sabem que os direitos de autor são adquiridos no mesmo momento da criação, não é preciso nenhum requisito formal. Isto é importante, pois se alguém tiver dúvidas se um trabalho de aula, por exemplo, tem direitos de autor, a resposta é sim, e os direitos são do aluno, portanto, em linhas gerais, podemos pensar que todas as fotos que usamos de internet, memes, vídeos, tudo, por efeito, está protegido. Se os usuários e os profissionais da informação se preocupassem um pouco mais com direitos autorais, conseguiríamos mudar uma legislação que não atende às necessidades da sociedade conectada e mais pessoas compartilhariam suas obras com licenças do tipo Creative Commons.

PerCursos: Como fica a questão da Lei dos Direitos Autorais: as redes sociais seguem a lei vigente do seu país ou do país onde foi produzida a informação que a rede social compartilhará?

Enrique Muriel-Torrado: As leis de direitos autorais, embora tenham como base acordos e convênios internacionais, são leis nacionais. Em princípio, cada empresa e cada pessoa deve cumprir a lei do país onde se encontre. No nosso caso, a Lei 9.610, de 19 de fevereiro de 1998 foi criada meses antes da fundação do buscador de Google. É fácil imaginar que uma lei da era pré-internet não está muito adaptada às necessidades de nossa sociedade da informação. 
PerCursos: Quais as implicações éticas que envolvem questões como a vigilância tecnológica e o rastreamento de nossas atividades na rede?

Enrique Muriel-Torrado: A vigilância tecnológica é um termo aplicado principalmente a empresas ou entidades, para conhecer a evolução do mercado, onde investir, quais são as novas pesquisas ou que novos produtos apresentam empresas do mesmo setor, entre outros. Em troca, a privacidade é um direito das pessoas. Do meu ponto de vista, é uma tarefa dos profissionais da informação orientar os usuários a viver on-line, ensinando vantagens e desvantagens de aplicativos, tecnologias e comportamentos na rede, para que as pessoas possam decidir o que fazer com conhecimento.É difícil de compreender as pessoas que afirmam não se importar com o direito à privacidade porque não têm nada a esconder. Como diria Edward Snowden (1), seria como dizer que não se importam com a liberdade de expressão porque não têm nada a dizer. A privacidade é um direito que deve ser respeitado e é importante que os usuários saibam como fazé-lo. (1, https://www.theguardian.com/us-news/video/2015/may/22/edward-snowden-rights-toprivacy-video )

PerCursos: A internet atual tem convergido para Internet das Coisas e Web Semântica. Este novo paradigma tem que impacto nas pesquisas que virão em $\mathrm{Cl}$ e na vida das pessoas?

Enrique Muriel-Torrado: A Internet das Coisas será a próxima revolução segundo os especialistas, e terá um melhor impacto na nossas vidas se conseguirmos antes debater algumas questões éticas atrás da hiperconexão de objetos que interagem entre eles e conosco. O avanço é indubitável, mais devemos estabelecer com clareza como se resolverão os dilemas que terão os dispositivos quando pensarem por eles mesmos (coisa que já fazem). Um exemplo é o carro autônomo, sem motorista. Devemos pensar como desejamos que ele escolha frente a um acidente: ir para a esquerda e atropelar várias pessoas ou para direita e arriscar a vida do motorista? Por outro lado, temos que continuar pensando na importância da privacidade e na segurança. Aqueles com aplicativos no telefone ou relógios inteligentes que registram todo o exercício feito durante o dia, imagino que não concordariam se a companhia que compila toda a 
informação compartilhasse seus dados com as seguradoras médicos, que poderiam rejeitá-lo se fizesse mais exercícios ou menos do que eles consideram o padrão, ou com bancos, que poderiam calcular o risco de dar um empréstimo.

A ciência e a tecnologia oferecem avanços maravilhosos que melhoram nossas vidas, e devemos tentar garantir que seja assim e não nos convertermos em simples produtos que geram dados para que outras empresas se aproveitem, e sem ter nosso consentimento informado.

PerCursos: Um dos aspectos da cultura digital é a emergência do e-book. Quais os conflitos atuais no que se refere ao direito dos autores? São os mesmos direitos de um livro em papel? Por exemplo, o e-book pode ser emprestado pelas bibliotecas?

Enrique Muriel-Torrado: Do meu ponto de vista, é um assunto muito relevante para os profissionais da informação. Quando compramos um livro em papel, adquirimos uma série de direitos. Podemos emprestá-lo, lê-lo as vezes que quisermos e onde quisermos, assim como vendê-lo, é uma propriedade material. Entretanto, quando compramos um ebook não compramos um arquivo epub ou pdf, compramos uma licença. As licenças são um tipo de contrato que oferecem acesso a uma obra e apontam o que podemos fazer com ela. Por exemplo, geralmente as licenças pró́bem a venda ou empréstimo de nosso livro legalmente adquirido a terceiros. Se comprarmos o clássico 1984, de George Orwell em papel, podemos emprestá-lo a várias pessoas, e um dia, se quisermos, vendê-lo. Com o mesmo livro adquirido em formato digital, não. Além disso, as licenças podem limitar desde onde acessamos a uma obra, como acontece com as grandes bases de dados do portal CAPES: precisamos estar dentro do campus da universidade (ou acessar mediante VPN) para ter acesso às bases de dados; se estivermos fora ou não tivermos configurado corretamente o VPN, então não podemos acessar. 
PerCursos: Comente sobre a emergência de movimentos como Copyleft ou Creative Commons em contraposição ao Copyright.

Enrique Muriel-Torrado: O movimento Copyleft não é contrário aos direitos autorais, ou pelo menos não todo o movimento (não devemos esquecer que onde existe poder, existe um contra poder). Embora seja um trocadilho, copyleft: cópia esquerda, como o contrário de copyright: cópia direita, está baseado nos direitos autorais; tanto é assim que melhoram os direitos de autor, para que os criadores e usuários tenham controle sobre nossas obras e possamos criar, utilizar e compartilhá-las segundo as condições que decidamos. Neste ponto, poderíamos falar sobre as licenças GNU em computação, fundamentais no software livre, e no âmbito da educação, das licenças Creative Commons, que apresentam seis licenças das quais duas são consideradas como livres e poderiam se encaixar dentro do conceito de copyleft (CC by e CC by-sa).

O Acesso Aberto é um movimento fundamental para o avanço da Ciência que fomenta o acesso e compartilhamento de informação científica. Este movimento se baseia nas licenças Creative Commons e, sem elas, seria muito difícil que pudesse existir.

A meu ver, os professores e alunos deveriam compartilhar suas obras sempre com uma licença Creative Commons. Para isso, simplesmente temos que entrar no site do projeto (https://creativecommons.org/choose/?lang=pt ), escolher a licença que quisermos, e escrever na nossa obra qual é a licença CC utilizada e um link para que se alguém não souber, possa se aprofundar mais no que permite ou não a licença. É uma forma simples e de graça de liberar e fomentar a educação para fazer do mundo um lugar um pouco melhor.

Recebida em: 30/09/2016 Aprovada em: 03/10/2016

Universidade do Estado de Santa Catarina - UDESC Centro de Ciências Humanas e da Educação - FAED

Revista PerCursos Volume 17 - Número 34 - Ano 2016 revistapercursos@gmail.com 